\title{
Fetal Outcomes among Hypertensive Pregnant Women at a Tertiary Maternity Hospital in Qatar, 2015-2017: A Case-Control Study
}

\author{
Gamal Sayed Ahmed ${ }^{1,2 *}$, Rayan Itani ${ }^{1}$, Abdullah Ibrahim ${ }^{1}$ and Aleah Almayah ${ }^{1}$ \\ ${ }^{1}$ Department of Obstetrics and Genecology, Women Wellness and Research Centre, Qatar \\ ${ }^{2}$ Weill Cornell Medical College Qatar, University of Dundee, UK
}

*Corresponding author: Gamal Sayed Ahmed, Department of Obstetrics and Gynecology, Women Wellness and Research Center, Hamad Medical Corporation, Doha, Qatar, 2. Weill Cornell Medical College Qatar, Doha, Qatar \& University of Dundee, UK.

To Cite This Article: Gamal Sayed Ahmed, Fetal Outcomes among Hypertensive Pregnant Women at a Tertiary Maternity Hospital in Qatar, 20152017: A Case-Control Study. Am J Biomed Sci \& Res. 2019 - 6(3). AJBSR.MS.ID.001027. DOI: 10.34297/AJBSR.2019.06.001027.

Received: 眥 November 18, 2019; Published: 恝 November 22, 2019

\section{Introduction}

According to population data, hypertensive disorders in pregnancy affect around $10 \%$ of pregnant women. They can be preexisting hypertension in $1 \%$, preeclampsia in around $2 \%$ and $6 \%$ pregnancy induced hypertension (hypertension without proteinuria). Preexisting hypertension, defined as a diastolic blood pressure $>90 \mathrm{mmHg}$ and/ora systolic $>\mathrm{BP}$ of $140 \mathrm{mmHg}$, is associated with increased risk of perinatal and maternal complications. Pregnancies affected with hypertension are associated with an increased risk of unfavorable fetal outcomes such as intrauterine growth restriction, low birth weight, and intrauterine fetal demise (IUFD) [1]. In Qatar, the exact risks to the fetus from chronic hypertension remain to be fully studied. The current study aims to look into the fetal outcomes among hypertensive pregnant women at a tertiary maternity facility in Doha, Qatar.

\section{Methods}

Our study is a hospital-based unmatched case-control study among pregnant women attending antenatal follow up at the Women Hospital/ Women Wellness and Research Center (Doha, Qatar) between January 1, 2015 and December 30, 2017. A simple random sampling technique was utilized to recruit 82 cases (pregnant women with chronic hypertension) and 82 controls (pregnant women without chronic hypertension). Descriptive and inferential statistics were conducted using Wizard Pro (version 1.9.26). A P-value less than 0.05 was considered statistically significant. For purpose of analysis we have used the following definitions: Preterm delivery - delivery below 37 weeks, low birth weight - below $2500 \mathrm{gms}$ at term, Foetal mortality - fetal death after 24 weeks, including still birth and neonatal death up to one month [2].

\section{Results}

Among the 164 participants, the mean gestational age at delivery for the cases and controls was about 36 and 37.6 weeks respectively ( $\mathrm{p}<0.001)$. Moreover, 51 cases $(54.9 \%)$ and 62 controls $(75.6 \%)$ underwent the nuchal translucency scan during their first trimester $(\mathrm{p}<0.32)$.

The rates of intrauterine growth restriction in the hypertensive group were double that of the control group (20.5\% and $10.7 \%)$ respectively. Furthermore, the rates of intrauterine foetal death were three times as much in the hypertensive group compared to the control group $(7.5 \%$ vs $2.5 \%)$. These numbers however didn't reach statistical significance.

Table 1: Distribution of foetal outcomes among new-borns of the cases and controls, WWRC 2015-2017.

\begin{tabular}{|c|c|c|c|}
\hline Variable & HTN (N=74) & $\begin{array}{c}\text { Non-HTN } \\
\mathbf{( N = 7 7 )}\end{array}$ & P-value \\
\hline IUGR \% & $20,5 \%$ & $10,7 \%$ & 0,21 \\
\hline IUFD \% & $7,5 \%$ & $2,5 \%$ & 0,15 \\
\hline $\begin{array}{c}\text { Gestational Age at } \\
\text { delivery (Mean } \pm \text { SD- } \\
\text { Weeks) }\end{array}$ & $35,97 \pm 0,8$ & $37,6 \pm 0,4$ & $<0,001$ \\
\hline $\begin{array}{c}\text { Foetal distress \% } \\
\text { grams) }\end{array}$ & $20,2 \%$ & $11,7 \%$ & 0,32 \\
\hline $\begin{array}{c}\text { Birth Weight (Mean } \pm \text { SD- } \\
\text { gram score at 1 minute }\end{array}$ & $2661,5 \pm 221,5$ & $3082,8 \pm 165$ & 0,003 \\
\hline APGAR $\%$ & $8,8 \pm 0,2$ & 0,039 \\
\hline $\begin{array}{c}\text { APGAR score at 5 } \\
\text { minutes }\end{array}$ & $9,1 \pm 0,6$ & $9,9 \pm 0,1$ & 0,014 \\
\hline $\begin{array}{c}\text { Admission to NICU \% } \\
\text { Congenital/genetic } \\
\text { anomalies \% }\end{array}$ & $19,2 \%$ & $14,9 \%$ & 0,49 \\
\hline $\begin{array}{c}\text { (I) } \% \\
4,1 \%\end{array}$ & 0,46 \\
\hline
\end{tabular}


Thirteen participants were lost to follow up (8 cases and 5 controls). Among those remaining (74 cases and 77 controls), there was a statistically significant difference in the birth weight and APGAR scores (at 1 and 5 minutes); which were lower among the new-borns of the hypertensive group $2661 \mathrm{~g}, 8.2,9.1$ ) than as compared to their controls $(3082 \mathrm{~g}, 8.8,9.9)$ (Graph 1-3, Table 1).

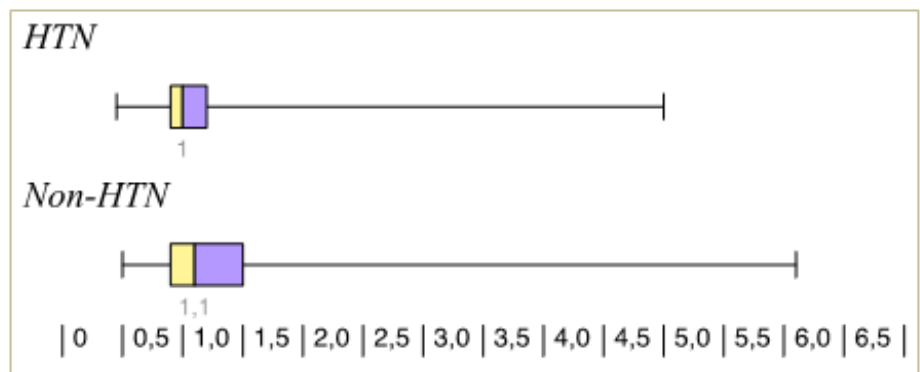

Graph 1: Nuchal Translucency among the two groups.

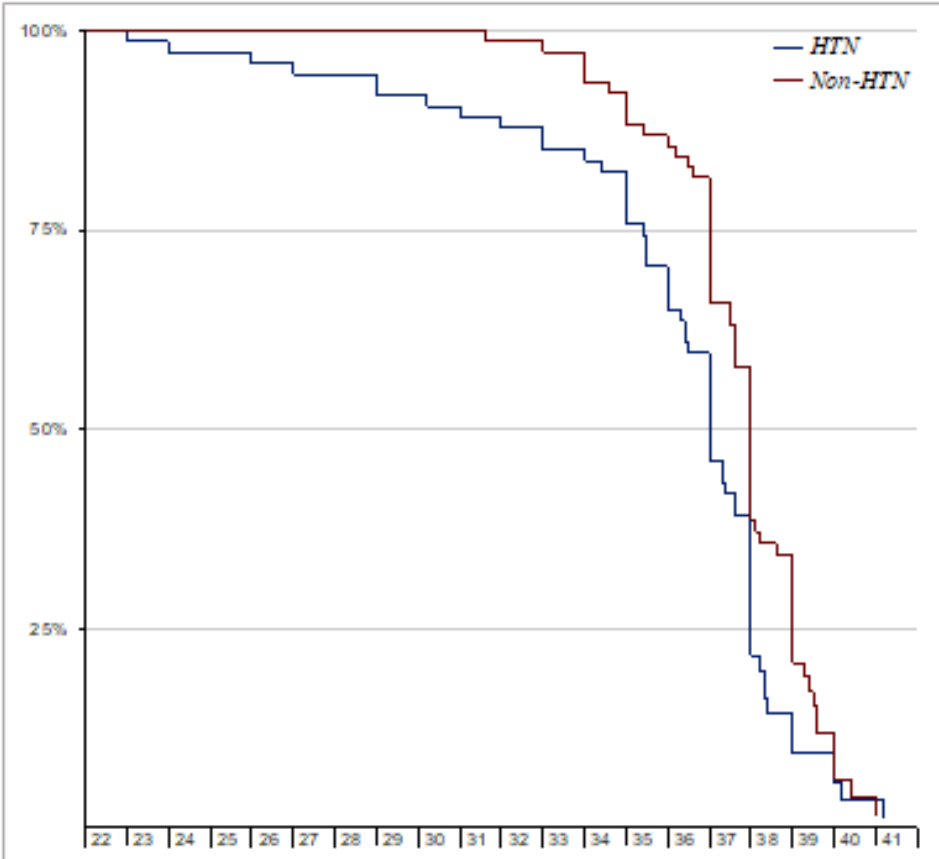

Graph 2: Kaplan Meier Curve of the Delivery Gestational Age of both groups.

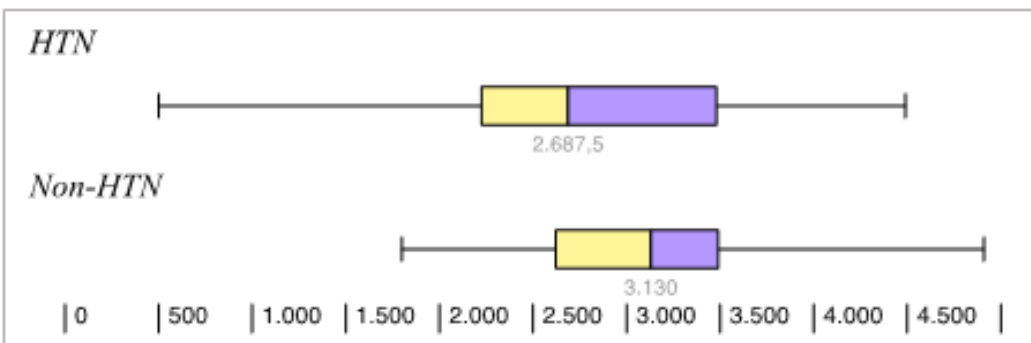

Graph 3: Median birth weight among the two groups.

\section{Discussion}

Chronic hypertension is defined by the American College of Obstetrics and Gynecology (ACOG) as blood pressure $\geq 140 \mathrm{~mm}$
$\mathrm{Hg}$ systolic and/or $90 \mathrm{~mm} \mathrm{Hg}$ diastolic before pregnancy or, before 20 weeks of gestation, use of antihypertensive medications before pregnancy, or persistence of hypertension for $>12$ weeks after delivery[3]. 
Chronic hypertension has been reported to affect 3-5\% of pregnancies according to different studies and has been reported as high as $8 \%$ in some3,5 This variation in reporting may be attributed to several factors [3-5]. Firstly, some of the population based studies are more than 20 years old and with the changing of population over the last 2 decades including higher maternal age at first pregnancy, metabolic syndrome, increasing obesity, it is likely that the prevalence of chronic hypertension in women entering pregnancy, in more than what has been previously reported [4-6].

Despite a reported increase in prevalence, many women do well in pregnancy. However chronic hypertension remains to have effects on both the mother and fetus. There is still an increase in placental abruption, intrauterine fetal death, small for gestational age babies and superimposed preeclampsia [7-9]. Although treating these patients with antihypertensive medications did seem to reduce the incidence of severe hypertension, it did not seem to affect the incidence of these outcomes [10].

In our study the incidence of small for gestational age babies (defined as estimated fetal weight of less than $10 \%$ for population norms), was found to be $20.5 \%$ which seems to be on the higher end of the prevalence rate compared to other studies. The incidence of small for gestational age babies in pregnant women with chronic hypertension in various population studies is around $10-20 \%$, even after adjustment for age, body mass index, smoking, parity, and diabetes mellitus $[7,11]$. It is possible that our numbers can be different, if we used our own population specific centiles for defining small for gestational age babies, which we currently don't use.

The mean gestational age at delivery for the hypertensive cases and controls in our study was around 36 weeks and 37.6 weeks respectively. Preterm delivery occurs in around 22.6 to $34.4 \%$ of pregnant women with chronic hypertension. This can reach up to $70 \%$ in women with severe hypertension [12]. Such early deliveries can be a result of shared decision making between patients and their health care providers when complications as abruption, intrauterine growth restriction and preeclampsia arise. In these cases, the optimum time of delivery is weighed against expectant management. This not surprisingly will lead to more inductions of labour and delivery at a preterm gestation.

The prevalence rate of perinatal death in other studies ranges around $2.9 \%-5.4 \%$ [13]. In our study the rate of perinatal death was $7.5 \%$ as opposed to $2.5 \%$ in the control group. Our results didn't reach statistical significance. This, however, was also one of the limitations of our study as our numbers were small and cannot be powered to look at fetal death, where much larger numbers are needed.

The incidence of neonatal unit admission in our study was $19.2 \%$ as compared to $14.9 \%$ in controls in our study. This seems to be similar to other studies where neonatal admission rates ranged from $15.7 \%$ to $26.4 \%$ [14].
The incidence of congenital anomalies in our study was $6.8 \%$ for the chronic hypertension group versus $4.1 \%$ for the control group. This confers with other studies which suggest that chronic hypertension is an independent risk factor for some increase in congenital anomalies, irrespective to medications that may carry some teratogenic effect [15].

\section{Conclusion}

More older mums are getting pregnant, and with the rising incidence of metabolic syndrome and obesity, more women will get pregnant who have chronic hypertension. Optimizing outcomes for these women and their babies should ideally start preconception, carefully planned and managed [16,17].

\section{References}

1. Saftlas AF, Olson DR, Franks AL, Atrash AK, Pokras R (1990) Epidemiology of preeclampsia and eclampsia in the United States, 1979-1986. Am J Obstet Gynecol 163(2): 460-465.

2. Yoder SR, Thornburg LL, Bisognano JD (2009) Hypertension in pregnancy and women of childbearing age. Am J Med 122(10): 890-895.

3. ACOG Committee on Practice Bulletins-Obstetrics (2002) ACOG practice bul- letin: diagnosis and management of preeclampsia and eclampsia. Obstet Gynecol 99: 159-167.

4. Bateman BT, Bansil P, Hernandez Diaz S, Mhyre JM, Callaghan WM, et al. (2012) Prevalence, trends, and outcomes of chronic hypertension: a nationwide sample of delivery admissions. Am J Obstet Gynecol 206(2): 134.e1-8.

5. Bayliss H, Churchill D, Beevers M, Beevers DG (2002) Anti-hypertensive drugs in pregnancy and fetal growth: evidence for "pharmacological programming" in the first trimester? Hypertens Pregnancy 21(2): 161174.

6. Ananth CV, Peedicayil A, Savitz DA (1995) Effect of hypertensive diseases in pregnancy on birthweight, gestational duration, and small-forgestational-age births. Epidemiology 6(4): 391-395.

7. Sibai BM (2002) Chronic hypertension in pregnancy. Obstet Gynecol 100: $369-377$

8. Rey E, Couturier A (1994) The prognosis of pregnancy in women with chronic hypertension. Am J Obstet Gynecol 171(2): 410-416.

9. McCowan LM, Buist RG, North RA, Gamble G (1996) Perinatal morbidity in chronic hypertension. Br J Obstet Gynaecol 103(2):123-129.

10. Abalos E, Duley L, Steyn DW, Henderson SmartDJ (2007) Antihypertensive drug therapy for mild to moderate hypertension during pregnancy. Cochrane Database Syst Rev (1): CD002252.

11. Catov JM, Nohr EA, Olsen J, Ness RB (2008) Chronic hypertension related to risk for preterm and term small for gestational age births. Obstet Gynecol 112(2pt 1): 290-296.

12. Sibai BM, Anderson GD (1986) Pregnancy outcome of intensive therapy in severe hypertension in first trimester. Obstet Gynecol 67(4): 517-522.

13. Zetterström K, Lindeberg SN, Haglund B, Hanson U (2008) The association of maternal chronic hypertension with perinatal death in male and female offspring: a record linkage study of 866,188 women. BJOG 115(11): 1436-1442.

14. Kate Bramham, Bethany Parnell, Catherine Nelson Piercy, Paul T Seed, Lucilla Poston, et al. (2014) Chronic hypertension and pregnancy outcomes: systematic review and meta-analysis. BMJ 348: g2301.

15. Li DK, Yang C, Andrade S, Tavares V, Ferber JR (2011) Maternal exposure to angiotensin converting enzyme inhibitors in the first trimester and risk of malformations in offspring: a retrospective cohort study. BMJ 343: d5931. 
16. Mathews TJ, Hamilton BE (2009) Delayed childbearing: more women are having their first child later in life. National Center for Health Statistics Data Brief 21: 1-8.
17. Seely EW, Ecker J (2014) Chronic hypertension in pregnancy. Circulation 129(11): 1254-1261. 